\title{
Influence of selected polymorphisms of the rennin- angiotensin system on the regulation of blood pressure during pregnancy
}

\begin{abstract}
Hypertension during pregnancy is a heterogeneous group of disorders with elevated blood pressure with or without proteinuria. The blood pressure regulation is a complex issue, and research on this issue has been present in the world literature for many years. The study was designed to evaluate the impact of the ACE I/D, AGT-235, AGT-174 polymorphisms on the regulation of blood pressure.

It is a case-control study. The study included 104 women with uncomplicated pregnancies in the control group and 75 pregnant women with hypertension disorders in the study group, hospitalized in the Perinatology and Obstetrics Department of the University Hospital in Cracow. Genomic DNA was extracted from peripheral blood leukocytes and polymorphisms were genotyped from all the patients. We analyzed the genotypes distribution and its association to blood pressure values, the time of hypertension occurrence, the medications needed to control it and the time postpartum till the blood pressure normalization in all the groups. A p-value $<0.05$ was considered as significant.

Clinical evaluation included many standard anthropometric measures like weight and height for the calculation of the BMI in the beginning of the pregnancy and blood pressure values. It may be concluded that there is no influence of studied polymorphisms not only on the regulation of blood pressure during pregnancy, but also on the time of the onset or pharmacological treatment of hypertension during pregnancy and the time after delivery needed to normalization of blood pressure values. Further studies on larger groups are needed.
\end{abstract}

Keywords: gestational hypertension, preeclampsia, blood pressure regulation, polymorphism, ACE I/D, AGT-235, AGT-174
Special Issue - 2015

\author{
Hubert Huras, Katarzyna Kusmierska-Urban, \\ Krzysztof Rytlewski \\ Department of Obstetrics and Perinatology, Jagiellonian \\ University Medical College, Poland
}

Correspondence: Katarzyna Kusmierska-Urban, 23 Kopernika St, 3I - 50 I Krakow, Poland, Tel +48 I2 42484 I2,

Email k.kusmierska@gmail.com

Received: January 07, 2015 | Published: April 6, 2015
Abbreviations: RAS, rennin-angiotensin system; ACE I/D, angiotensin-converting enzyme insertion/deletion; AGT, angiotensynogen; DNA, deoxyribonucleic acid; EDTA, ethylene diamine tetra acetic acid; PCR, polymerase chain reaction; NHBPEPWG, National high blood pressure education program working group; BMI, body mass index; MAP, mean arterial pressure.

\section{Introduction}

The blood pressure regulation is a complex issue and research on this issue has been present in the world literature for many years. Some studies suggested that the renin-angiotensin system (RAS), not only takes part in regulating blood pressure and fluid and electrolyte balance, ${ }^{1}$ but also have an impact on the "physiological remodeling" of spiral arteries throughout pregnancy. ${ }^{2}$ During normal pregnancy the RAS is stimulated including plasma renin activity or angiotensinogen, angiotensin II and aldosterone levels elevation. ${ }^{3}$

$\mathrm{ACE}$ and the angiotensinogen (AGT) genes sequences have identified a variety of polymorphisms which may contribute to many kinds of hypertension. ${ }^{4-6}$ Plasma levels of ACE have been associated with the insertion/deletion (I/D) polymorphism in intron 16 of the ACE gene. As the ACE I/D polymorphism was accounted for $47 \%$ of total phenotypic variance of serum ACE, so it is one of the most important polymorphism which contributes to the variability of the ACE level and consequently to angiotensin II levels. ${ }^{7}$ The AGT is also a major component of RAS. The AGT-235 (M235T) polymorphism of the AGT gene is associated with increased plasma levels of AGT. ${ }^{8}$ Still, not many studies have been conducted upon the AGT-174 polymorphism.

The aim of this study was to evaluate the probable impact of the ACE I/D, AGT-235 and the AGT-174 polymorphisms on the blood pressure regulation during the pregnancy and additional clinical aspects of the disease as the time of its occurrence, pharmacological treatment and the time of blood pressure normalization.

\section{Material and methods}

179 pregnant patients were randomly enrolled for the study out of the women hospitalized in the Perinatology and Obstetrics Department of the University Hospital in Cracow (Poland). It is a case-controlled study. Hypertension and proteinuria were defined according to NHBPEP-WG. ${ }^{9}$ The hypertensive patients were divided into smaller groups depending on the final diagnosis of preeclampsia, gestational hypertension or chronic hypertension in number of 29,35 and 11 patients respectively. The hypertensiveness was considered if the systolic/diastolic blood pressure was $\geq 140 / 90 \mathrm{mmHg}$ in two separated measurements. If the proteinuria occurred with the hypertension at the end of the 20th week of pregnancy we diagnosed the preeclampsia. The exclusion criteria included: multiple pregnancy, stillbirth, fetal anomalies, patients with renal, liver or heart diseases as well as the withdrawal of patient's consent. 
104 normotensive pregnant women were enrolled as a control group aged from 18 to 39 years old. Written informed consent was obtained from all the patients enrolled in this study and this study was approved by Ethic Committee of Jagiellonian University. Each patient was interviewed and detailed medical history like gravidity, parity, week of gestation was taken. Clinical evaluation included standard anthropometric measures like weight and height for the calculation of the BMI in the beginning and in the end of the pregnancy, blood pressure (systolic, diastolic and MAP), time and a method of the delivery and the birth weight with a percentile. Samples of venous blood from all the patients were collected into EDTA tubes while performing standard medical procedures during hospitalization. The blood samples were kept at $-80^{\circ} \mathrm{C}$ till all of the samples were gathered and analyzed at the same time.

The genomic DNA was extracted from peripheral blood leukocytes. The DNA extraction was performed with Kit High Pure PCR Template Preparation Kit. The DNA quality and quantity were assessed on a spectrophotometer NanoDrop ND-1000. Genotyping was performed by investigators blinded to clinical status using the standardized protocols. ${ }^{10-12}$ The characteristics of study groups were compared according to by the Kruskal-Wallis test, Mann-Whitney test, Fisher's exact test, chi-square test, Classical analysis of variance and the posthoc Tuckey test. The distributions of the genotype variants among studied subjects were compared by the chi-squared analysis and test Fisher's exact. The odds ratios were calculated as a measure of the association between the genotypes and clinical phenotypes. For each odds ratio, $p$ values and $95 \%$ confidence intervals were calculated. A $p$ value of $<0.05$ was considered as statistically significant. The results were analyzed IBM SPSS Statistics v.20.

\section{Results and discussion}

The anthropometric characteristics of the studied populations are presented in Table 1. Pregnant women with hypertension and normotensive pregnant patients were homogeneous for the gestational history and place of living (data not shown), but significant differences were found in the age and weight measurements.

Table I The anthropometric characteristics

\begin{tabular}{|c|c|c|c|c|c|}
\hline & Chronic hypertension & Gestational hypertension & Preeclampsia & Control group & $\mathbf{p}$ \\
\hline \multicolumn{6}{|l|}{ Height (cm) } \\
\hline mean [SD] & $n=10$ & $n=34$ & $\mathrm{n}=27$ & $n=85$ & \\
\hline \multirow[t]{2}{*}{$\min -\max$} & $165.3 \pm 6.6$ & $165.9 \pm 6.1$ & $163.1 \pm 6.2$ & $165.8 \pm 6.5$ & $\mathrm{pA}=0.249$ \\
\hline & {$[155-174]$} & {$[150-176]$} & {$[150-175]$} & {$[150-186]$} & \\
\hline \multicolumn{6}{|c|}{ Body weight before pregnancy (kg) } \\
\hline mean $[S D]$ & $n=10$ & $n=31$ & $n=25$ & $n=77$ & $\mathrm{pKW}=0.00 \mathrm{I}$ \\
\hline \multirow[t]{2}{*}{$\min -\max$} & $83.1 \pm 23.0$ & $69.2 \pm 12.3$ & $61.1 \pm 13.8$ & $62.7 \pm 9.8$ & I \\
\hline & {$[54-117]$} & [48-104] & [45-93] & [42-86] & \\
\hline \multicolumn{6}{|c|}{ BMI before pregnancy $\left(\mathrm{kg} / \mathrm{m}^{2}\right)$} \\
\hline mean $[S D]$ & $n=10$ & $n=31$ & $\mathrm{n}=25$ & $n=77$ & $\mathrm{pKW}=0.002$ \\
\hline \multirow[t]{2}{*}{$\min -\max$} & $30.3 \pm 7.8$ & $25.3 \pm 5.1$ & $22.8 \pm 4.2$ & $22.8 \pm 3.4$ & 2 \\
\hline & {$[21.6-41.5]$} & {$[|7.9-4| .7]$} & {$[17.2-32.2]$} & {$[|6.8-3| .6]$} & \\
\hline \multicolumn{6}{|c|}{ Weight gain during pregnancy (kg) } \\
\hline mean [SD] & $n=10$ & $n=31$ & $n=25$ & $n=78$ & \\
\hline \multirow[t]{2}{*}{$\min -\max$} & $9.7 \pm 9.2$ & $15.2 \pm 6.2$ & $16.0 \pm 7.1$ & $14.9 \pm 5 . \mid$ & $\mathrm{pKW}=0.27 \mathrm{I}$ \\
\hline & {$[-15-18]$} & {$[6-30]$} & {$[6-36]$} & {$[5-32]$} & \\
\hline \multicolumn{6}{|c|}{ Maternal age (years) } \\
\hline mean $[S D]$ & $34.9 \pm 3.8$ & $30.6 \pm 6.2$ & $30.5 \pm 4.3$ & $29.1 \pm 4.4$ & $\mathrm{pMW}=0.004$ \\
\hline $\min -\max$ & [28-39] & [21-44] & [25-39] & [18-39] & 3 \\
\hline
\end{tabular}

A, analysis of variance (ANOVA) for single classifications; $\mathrm{KW}$, kruskal-wallis test, MW, mann-whitney test

1. post-hoc Tuckey test chronic hypertension group vs. gestational hypertension $\mathrm{p}=0.012$; chronic hypertension vs. preeclampsia $\mathrm{p}<0.001$; chronic hypertension vs. control group, $\mathrm{p}<0.001$, other pairwise comparisons $\mathrm{p}>0.05$

2. post-hoc Tuckey test chronic hypertension vs. gestational hypertension $\mathrm{p}=0,011$; chronic hypertension vs preeclampsia $\mathrm{p}<0,001$; chronic hypertension vs. control group $\mathrm{p}<0,001$; gestational hypertension vs. control group $\mathrm{p}=0,028$; other pairwise comparisons $\mathrm{p}>0,05$

3. post-hoc Tuckey test: chronic hypertension group vs. gestational hypertension $\mathrm{p}=0.045$; chronic hypertension vs. preeclampsia $\mathrm{p}=0.044$; chronic hypertension vs. the control group, $\mathrm{p}=0.001$; other pairwise comparisons $\mathrm{p}>0.05$ 
Women with chronic hypertension presented a higher body weight and BMI before the pregnancy, than those with gestational hypertension and preeclampsia. Women with chronic hypertension also showed a higher body weight and BMI than the control group. There were no statistically significant differences between pregnant women in height and weight gain during pregnancy. The similar differences were seen when comparing the age of patients, as patients with chronic hypertension were older than patients in the rest of the groups with statistical importance.

The study analyzed the relationship of polymorphisms of the reninangiotensin with values of the blood pressure in pregnant women. When comparing the average and the maximum values of systolic, diastolic and mean (MAP mean artery pressure) pressure based on the distribution of the genotypes of the polymorphisms tested, there were no statistically significant differences. However, a closer examination of the results shows a trend consistent with the literature. The ACE I/D, AGT-235, AGT-174 polymorphisms were in the Hardy-Weinberg equilibrium.

The average pressure values were highly comparable between the groups, while the maximum pressure values were the lowest in the homozygous deletion (DD) group, with no statistical significance (Table 2). When comparing the average and maximum values of systolic and diastolic pressure, higher values were observed for genotype homozygous for a mutant variant of the T AGT-174, although with no significant differences (Table 3). The analysis of the distribution of values of blood pressure based on the genotype AGT235 did not show a statistically significant difference. Only observed higher values of maximum systolic, diastolic and MAP in the group AGT-235 heterozygotes CT compared to homozygous CC, TT (Table 4).

When analyzing the week of pregnancy in which the hypertension occurred depending on the genotype of the ACE, AGT-174 and AGT-235 genes no statistically important conclusions can be made Hypertension occurred nearly five weeks earlier in the DD patients of the ACE gene compared to patients II. Similarly, in the patients homozygous CC of AGT-174 polymorphism hypertension was diagnosed four weeks earlier than in the heterozygotes CT (Table 5), with no statistical significance. The detailed analysis of the number of medications needed to control the hypertension and time of blood pressure normalization after delivery showed no statistically important differences between the group depending on genotypes (data not shown).

Available results show evidence of the influence of body weight and ACE genotype on the appearance of hypertension. Although the study was conducted on a group of non-pregnant patients, the increased risk of hypertension in carriers of the D allele with obesity have been showed. ${ }^{13}$ A closer analysis of I / D polymorphism of the ACE gene showed significant differences according not only to height and weight but also to gender and age, when tested for the systolic blood pressure and diastolic blood pressure between the homozygous (DD, II) and heterozygous (ID), ${ }^{14}$ It points at a numerous relationships between changes in multi-phenotype and genotype, hindering direct comparisons between the study groups. Such conclusions also result from this work. The ID heterozygotes have higher values of maximum pressure, both systolic, diastolic and MAP, but without reaching statistical significance threshold. Other studies contradict the possible impact of the ACE gene mutation on the incidence of hypertension ${ }^{15}$ and blood pressure regulation, ${ }^{16}$ but these studies have not been conducted in a group of pregnant women.
Table 2 Average and maximum values of blood pressure in pregnant depending on the genotype of the ACE gene

\begin{tabular}{|c|c|c|c|c|}
\hline ACE & $\begin{array}{l}\text { DD } \\
n=44\end{array}$ & $\begin{array}{l}\text { ID } \\
n=86\end{array}$ & $\begin{array}{l}\text { II } \\
n=46\end{array}$ & \\
\hline \multicolumn{5}{|c|}{ The average systolic blood pressure $[\mathrm{mmHg}]$} \\
\hline mean $[S D]$ & $124.3 \pm 17.6$ & $123.7 \pm 15.7$ & $126.2 \pm 16.1$ & $\mathrm{pA}=0.702$ \\
\hline $\min -\max$ & [100-162] & [90-164] & {$[100-179]$} & \\
\hline
\end{tabular}

The average diastolic blood pressure $[\mathrm{mmHg}]$

$\begin{array}{lllll}\text { mean [SD] } & 77.8 \pm 10.9 & 77.3 \pm 10.7 & 78.6 \pm 10.6 & \mathrm{PA}=0.807 \\ \min -\max & {[60-98]} & {[60-105]} & {[60-101]}\end{array}$

The average MAP $[\mathrm{mmHg}]$

$\begin{array}{lllll}\text { mean [SD] } & 93.3 \pm 12.5 & 92.8 \pm 12.0 & 94.5 \pm 12.0 & \mathrm{PA}=0.750 \\ & & & {[76.7-} & \\ \min -\max & {[73.3-115.0]} & {[70-122.3]} & 127.0] \\ \text { ACE } & \text { DD } & \text { ID } & \text { II } \\ & \mathrm{n}=23 & \mathrm{n}=38 & \mathrm{n}=21\end{array}$

The maximal systolic pressure $[\mathrm{mmHg}]$

$\begin{array}{lllll}\operatorname{mean}[\mathrm{SD}] & 156.5 \pm 24.9 & 168.5 \pm 19.8 & 163.8 \pm 21.7 & \mathrm{PA}=0.120 \\ \min -\max & {[110-230]} & {[130-210]} & {[120-200]} & \end{array}$

The maximal diastolic pressure $[\mathrm{mmHg}]$

$\begin{array}{lllll}\operatorname{mean}[\mathrm{SD}] & 98.3 \pm 11.6 & 104.5 \pm 12.6 & 102.3 \pm 15.7 & \mathrm{pA}=0.210 \\ \min -\max & {[70-120]} & {[80-140]} & {[70-140]} & \end{array}$

The maximal MAP $[\mathrm{mmHg}]$

mean $[S D] \quad|17.7 \pm| 5.5 \quad|25.8 \pm| 4 .|\quad| 22.8 \pm|6| \quad p A=$.

$\min -\max \quad[87-157] \quad[97-157] \quad[87-157]$

A, classical analysis of variance; MAP, mean arterial pressure.

Table 3 Average and maximum values of blood pressure in pregnant depending on the genotype of the AGT-174 gene

\begin{tabular}{llll}
\hline \multirow{2}{*}{ AGT-I74 } & CC & CT & TT \\
$n=117$ & $n=55$ & $n=4$ \\
\hline
\end{tabular}

The average systolic blood pressure $[\mathrm{mmHg}]$

$\begin{array}{lllll}\operatorname{mean}[S D] & 125.0 \pm 15.5 & 123.0 \pm 17.7 & 129.0 \pm 16.5 & \\ \min -\max & {[100-164]} & {[90-179]} & {[110-150]} & \mathrm{pA}=0.646\end{array}$

The average diastolic blood pressure $[\mathrm{mmHg}]$

$\begin{array}{lllll}\text { mean }[S D] & 78.2 \pm 10.6 & 76.8 \pm 11.3 & 81.5 \pm 2.4 & \\ \min -\max & {[60-102]} & {[60-105]} & {[80-85]} & \end{array}$

The average MAP $[\mathrm{mmHg}]$

$\begin{array}{lllll}\text { mean [SD] } & 93.8 \pm I \mid .8 & 92.2 \pm \mid 3.0 & 97.3 \pm 6.9 & \\ & {[73.3-} & {[70.0-} & {[90.0-} & \\ \min -\max & 122.0] & 127.0] & 106.7] & \mathrm{PA}=0.58 \mathrm{I} \\ & \mathrm{CC} & \mathrm{CT} & \mathrm{TT} & \\ \text { AGT-I74 } & \mathrm{n}=6 \mathrm{I} & \mathrm{n}=19 & \mathrm{n}=2 & \end{array}$




\begin{tabular}{llll}
\multicolumn{2}{c}{ Table Continued } \\
\hline \multirow{2}{*}{ AGT-I74 } & CC & CT & TT \\
& $n=117$ & $n=55$ & $n=4$ \\
\hline
\end{tabular}

The maximal systolic pressure $[\mathrm{mmHg}]$

$\begin{array}{lllll}\text { mean }[S D] & 163.6 \pm 23.0 & 163.8 \pm 20.8 & 175.0 \pm 7.1 & \\ \min -\max & {[110-230]} & {[120-200]} & {[170-180]} & \mathrm{PA}=0.778\end{array}$

The maximal diastolic pressure $[\mathrm{mmHg}]$

$\begin{array}{lllll}\operatorname{mean}[S D] & 101.8 \pm 13.6 & 103.0 \pm 13.2 & 105.0 \pm 7.1 & \\ \min -\max & {[70-140]} & {[70-120]} & {[100-110]} & \mathrm{pA}=0.905\end{array}$

The maximal MAP $[\mathrm{mmHg}]$

\begin{tabular}{|c|c|c|c|c|}
\hline mean $[S D]$ & $122.4 \pm 15.6$ & $123.3 \pm 14.9$ & $128.3 \pm 2.4$ & \\
\hline & [87-157] & [87-|40] & [127-130] & \\
\hline
\end{tabular}

A, classical analysis of variance; MAP, mean arterial pressure.

Table 4 Average and maximum values of blood pressure in pregnant depending on the genotype of the AGT-235 gene

\begin{tabular}{llll}
\hline \multirow{2}{*}{ AGT-235 } & TT & CT & CC \\
& $n=43$ & $n=117$ & $n=16$ \\
\hline
\end{tabular}

The average systolic blood pressure $[\mathrm{mmHg}]$

\begin{tabular}{|c|c|c|c|c|}
\hline mean $[S D$ ] & $124.8 \pm 16.0$ & $124.5 \pm 17.0$ & $|23.8 \pm| \mid .3$ & \multirow{2}{*}{$\mathrm{pA}=0.975$} \\
\hline $\min -\max$ & {$[100-160]$} & {$[90-179]$} & {$[106-|4|]$} & \\
\hline \multicolumn{5}{|c|}{ The average diastolic blood pressure $[\mathrm{mmHg}]$} \\
\hline mean $[\mathrm{SD}]$ & $77.9 \pm 10.0$ & $77.5 \pm 11.4$ & $79.2 \pm 6.4$ & \multirow{2}{*}{$\mathrm{pKW}=0.425$} \\
\hline $\min -\max$ & [60-102] & [60-105] & [67-88] & \\
\hline
\end{tabular}

The average MAP $[\mathrm{mmHg}]$

$\begin{array}{llll}\text { mean [SD] } & 93.6 \pm 1 \mid 1.6 & 93.2 \pm 12.8 & 94.0 \pm 7.6 \\ \min -\max & {[73.3-120.0]} & {[70.0-127.0]} & {[81.0-} \\ \text { AGT-235 } & \text { TT } & \text { CT } & \text { CC } \\ & \mathrm{n}=21 & \mathrm{n}=5 \mathrm{I} & \mathrm{n}=10\end{array}$

The maximal systolic pressure $[\mathrm{mmHg}]$

$\begin{array}{ccccc}\operatorname{mean}[S D] & 157.2 \pm 22.5 & 167.7 \pm 21.6 & 159.0 \pm 22.3 & \mathrm{pA}=0.143 \\ \min -\max & {[110-200]} & {[120-230]} & {[130-190]} & \end{array}$

The maximal diastolic pressure $[\mathrm{mmHg}]$

$\begin{array}{lllll}\operatorname{mean}[\mathrm{SD}] & 98.2 \pm 12.1 & 104.2 \pm 12.7 & 100.5 \pm 17.4 & \\ \min -\max & {[70-115]} & {[70-140]} & {[80-140]} & \mathrm{PA}=0.205\end{array}$

The maximal MAP $[\mathrm{mmHg}]$

$\begin{array}{lllll}\operatorname{mean}[S D] & |17.9 \pm| 4.8 & |25.3 \pm| 4.5 & \mid 20.0 \pm 18.1 & \mathrm{PA}=0.138 \\ \min -\max & {[87-140]} & {[87-157]} & {[97-157]} & \end{array}$

A, classical analysis of variance; MAP, mean arterial pressure.

The AGT-174 (T174M) polymorphism of AGT gene appears to play a role in the regulation of blood pressure. It has been shown that homozygous carriers of the variant 174T, or C allele according to the new nomenclature, have lower systolic, diastolic, and mean arterial pressure, than heterozygotes or homozygotes the $174 \mathrm{M}$ variant (allele
T according to the new nomenclature). ${ }^{17}$ These results are consistent with the results of this work, though due to the small sample size, no statistical significance was obtained. Another study on a group of men, but not on a group of women, confirmed the role of the AGT-174 polymorphism in the regulation of blood pressure and demonstrated the highest systolic blood pressure in carriers of the mutant allele T. ${ }^{18}$ However, in other studies on large groups without distinction of pregnancy, there was no effect of this polymorphism on the regulation of blood pressure. ${ }^{19,20}$ The contribution of this polymorphism in the pathophysiology of hypertension requires further study in a group of pregnant women.

Table 5 Week of pregnancy in which the hypertension occurred depending on the genotype of the ACE.AGT-174 and AGT-235 genes

\begin{tabular}{|c|c|c|c|c|}
\hline ACE & $\begin{array}{l}D D \\
n=18\end{array}$ & $\begin{array}{l}\text { ID } \\
n=32\end{array}$ & $\begin{array}{l}\text { II } \\
n=17\end{array}$ & \\
\hline $\begin{array}{l}\text { Week of } \\
\text { pregnancy }\end{array}$ & $26.3 \pm 11.2$ & $28.2 \pm 9.8$ & $31 . \pm 4.6$ & \multirow{2}{*}{$\mathrm{pKW}=0.532$} \\
\hline $\begin{array}{l}\operatorname{mean}[S D] \text { min- } \\
\max \end{array}$ & [6-39] & [4-39] & {$[21-39]$} & \\
\hline \multirow{2}{*}{ AGT-I74 } & $\mathrm{CC}$ & CT & TT & \multirow{6}{*}{$\mathrm{pA}=0.285$} \\
\hline & $n=50$ & $n=16$ & $n=1$ & \\
\hline $\begin{array}{l}\text { Week of } \\
\text { pregnancy }\end{array}$ & $27.6 \pm 9.3$ & $31.7 \pm 9.1$ & $24.0 \pm[-]$ & \\
\hline $\begin{array}{l}\max \\
\max \end{array}$ & [5-39] & [4-39] & [24-24] & \\
\hline \multirow{2}{*}{ AGT-235 } & $\mathrm{TT}$ & $\mathrm{CT}$ & $\mathrm{CC}$ & \\
\hline & $n=18$ & $n=42$ & $n=7$ & \\
\hline $\begin{array}{l}\text { Week of } \\
\text { pregnancy }\end{array}$ & $29.4 \pm 8.4$ & $28.0 \pm 10.1$ & $29.9 \pm 7.1$ & \multirow[b]{2}{*}{$\mathrm{pA}=0.793$} \\
\hline $\begin{array}{l}\operatorname{mean}[\mathrm{SD}] \mathrm{min}- \\
\max \end{array}$ & [5-39] & [4-39] & [23-39] & \\
\hline
\end{tabular}

$A$, classical analysis of variance; $\mathrm{KW}$, kruskal-wallis test.

Analysis of gene AGT-235 polymorphism in many studies did not show its' impact on the regulation of blood pressure, without distinguishing between pregnant women ${ }^{11,16,20}$ which is consistent with the present study. When examining the current literature the authors have found no studies about associations between genotypes on pharmacotherapy of hypertension in pregnancy and postpartum period needed for blood pressure normalization.

\section{Conclusion}

On the basis of the collected material, the role of the ACE I/D, AGT-235, AGT-174 polymorphisms in the regulation of blood pressure was not shown. It may be concluded that there is no influence of these polymorphisms not only on the regulation of blood pressure during pregnancy, but also on the time of the onset or pharmacological treatment of hypertension during pregnancy and the time after delivery needed to normalization of blood pressure values. Researches on a larger study groups are needed.

\section{Acknowledgments}

This research was supported by a funding from Jagiellonian University Medical College. 


\section{Conflicts of interest}

The authors declare there is no conflict of interests.

\section{References}

1. Griendling KK, Murphy TJ, Alexander RW. Molecular biology of the renin angiotensin system. Circulation. 1993;87(6):1816-1828.

2. Morgan T, Craven C, Ward K. Human spiral artery renin-angiotensin system. Hypertension. 1998;32(4):683-687.

3. Langer B, Grima M, Coquard C, et al. Plasma active renin, angiotensin $\mathrm{I}$, and angiotensin II during pregnancy and in preeclampsia. Obstet Gynecol. 1998;91(2):196-202.

4. Kaplan I, Sancaktar E, Ece A, et al. Gene polymorphisms of adducin GLY460TRP, ACE I/D, AND AGT M235T in pediatric hypertension patients. Med Sci Monit. 2014;20:1745-1750.

5. Ward K, Hata A, Jeunemaitre X, et al. A molecular variant of angiotensinogen associated with preeclampsia. Nat Genet. 1993;4(1):5961.

6. Kim HS, Krege JH, Kluckman KD, et al. Genetic control of blood pressure and the angiotensinogen locus. Proc Natl Acad Sci U S A. 1995;92(7):2735-2739.

7. Rigat B, Hubert C, Alhenc-Gelas F, et al. An insertion-deletion polymorphism in the angiotensin I-converting enzyme gene accounting for half the variance of serum enzyme levels. J Clin Invest. 1990;86(4):1343-1346.

8. Campbell CY, Fang BF, Guo X, et al. Associations between genetic variants in the ACE, AGT, AGTR1 and AGTR2 genes and renal function in the Multi-ethnic Study of Atherosclerosis. Am J Nephrol. 2010;32(2):156-162.

9. Report of the National High Blood Pressure Education Program Working Group on High Pressure in Pregnancy. Am J Obstet Gynecol. 2000;183(1):S1-S22.

10. Rigat B, Hubert C, Corvol P, et al. PCR detection of the insertion/deletion polymorphism of the human angiotensin converting enzyme gene (DCP1) (dipeptidyl carboxypeptidase 1). Nucleic Acids Res. 1992;20(6):1433.
11. Niu T, Yang J, Wang B, et al. Angiotensinogen gene polymorphisms M235T/T174M: no excess transmission to hypertensive Chinese Hypertension. 1999;33(2):698-702.

12. Olsson M, Annerbrink K, Westberg L, et al. Angiotensin-related genes in patients with panic disorder. Am J Med Genet B Neuropsychiatr Genet. 2004;127B(1):81-84

13. Mehri S, Mahjoub S, Hammami S, et al. Renin-angiotensin system polymorphisms in relation to hypertension status and obesity in a Tunisian population. Mol Biol Rep. 2012;39(4):4059-4065.

14. Turner ST, Boerwinkle E, Sing CF. Context-dependent associations of the ACE I/D polymorphism with blood pressure. Hypertension. 1999;34(4 Pt 2):773-778.

15. Jeunemaitre X, Lifton RP, Hunt SC, et al. Absence of linkage between the angiotensin converting enzyme locus and human essential hypertension. Nat Genet. 1992;1(1):72-75.

16. Mondorf UF, Russ A, Wiesemann A, et al. Contribution of angiotensin I converting enzyme gene polymorphism and angiotensinogen gene polymorphism to blood pressure regulation in essential hypertension. $\mathrm{Am}$ J Hypertens. 1998;11(2):174-183.

17. Hegele R, Brunt JH, Connelly PW. Genetic and Biochemical Factors Associated With Variation in Blood Pressure in a Genetic Isolate. Hypertension. 1996;27(2):308-312.

18. Hegele RA, Brunt JH, Connelly PW. A polymorphism of the angiotensinogen gene associated with variation in blood pressure in a genetic isolate. Circulation. 1994;90(5):2207-2212.

19. Niu T, Chen C, Yang J, et al. Blood pressure and the T174M and M235T polymorphisms of the angiotensinogen gene. Ann Epidemiol. 1999;9(4):245-253.

20. Renner W, Nauck M, Winkelmann BR, et al. LURIC Study team Association of angiotensinogen haplotypes with angiotensinogen levels but not with blood pressure or coronary artery disease: the Ludwigshafen Risk and Cardiovascular Health Study. J Mol Med (Berl). 2005;83(3):235-239. 